\title{
Cultural factors in livestock emergency management
}

Peer Reviewed

\section{Dr Marjan Leneman ${ }^{1}$ Ir Eva Jordans ${ }^{2}$ Dr Katinka de Balogh ${ }^{3}$}

1. Research consultant, Nijmegen,

The Netherlands.

2. Independent Management Consultant, Groningen The Netherlands.

3. Food and Agriculture Organization, Bangkok, Thailand.

\section{SUBMITTED}

8 February 2021

\section{ACCEPTED}

2 June 2021

\section{DOI}

www.doi.org/10.47389.36.3.69

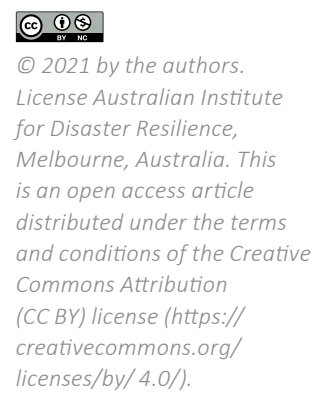

\section{Introduction}

Disaster mitigation and emergency response are contextual and complex. This is especially the case with disasters where there are high levels of uncertainty, for example, volcanic eruptions. Despite advanced monitoring and early warning systems, communication networks and measures, such as implementation of evacuations, casualties occur among people living in high-risk hazard zones of volcanoes who are often dependant on small-scale or subsistence farming.

Attending to animals and crops as long as possible is often given as a reason to delay evacuation (Mei et al. 2013) and residents are reluctant to leave and keen to return. Furthermore, in 2010 the spiritual gatekeeper of Mount Merapi in Indonesia and the people who took guidance from him did not evacuate in time and many died. Reports and case studies on evacuation reluctance or refusal concern many places in the world. Residents may consider risk rationales that differ from scientific risk calculation and modelling.

An understanding of why people are reluctant to evacuate or choose not to evacuate requires insights into the context of communities and their risk rationales. To explore this the following questions are considered:

- How do cultural (incl. psychological) factors play a role in evacuation reluctance prior to and during volcanic eruptions and what do they mean in terms of risk perceptions and assessments, and people and animal evacuation?

- How can livestock emergency preparedness (and reconstruction) programs be designed and implemented in a culturally sensitive manner?

\section{Methodology}

Complex societal issues, such as culture and how it influences emergency management, are difficult to scientifically capture. They encompass broad topics that are too many for a single discipline and can become fragmented in a multi-disciplinary endeavour. Thus, an inter-disciplinary and phenomenological approach was adopted for this study. Contrary to a neo-positivist approach (common in the life and natural sciences), phenomenological approaches take context into consideration. Observations and reflections of patterns and how knowledge, including science, is socially constructed are part of this approach (Latour \& Woolgar 1986).

\section{Abstract}

Despite the institutionalisation of volcanic eruption early warning and response systems, casualties are still seen among local farmers who are reluctant to evacuate. Farmers may also prematurely return to their farms to save livelihoods and take care of animals. Case studies and media reports show the importance of understanding the cultural beliefs of residents when developing emergency plans. By reviewing literature from different scientific disciplines in relation to volcanic eruptions and livestock emergency preparedness, differences can be identified in the underlying risk and control paradigms, including the meaning given to volcanoes and livestock. Concurrently, livestock emergency preparedness approaches fall short of people-orientation. Using selected studies that consider these aspects, a people-centred and culture-sensitive framework to improve local learning and participation in emergency preparedness is offered. With disaster events becoming more frequent, participatory learning is useful to strengthen emergency management and preparedness programs. 
A literature review was conducted from different scientific disciplines related to culture, livelihood and risk that correlated to the research questions. This was linked to studies concerning response to disasters, particularly to volcanic eruptions and people and livestock evacuations. This showed a pattern of evacuation reluctance reasons regarding the first research question and an observation for the second research question. A pattern of recurring psychological-cultural reasons for not evacuating as shown in the literature included:

- religious beliefs

- relying on traditional coping mechanisms

- mistrust of outsiders

- compromised resilience

- false sense of safety or perceived immunity.

Most commonly mentioned evacuation reluctance reasons in media articles were animals and religious beliefs. Analysis showed that livestock emergency programs and frameworks were focused on livestock rather than the people who owned livestock. Searches for example studies that confirmed or denied the pattern and observation were undertaken to select for ways to address culture in livestock emergency management and to develop a framework for a people-centred approach in emergency preparedness and response.

Applications of MEDLINE/PubMed, Web of Science, Google Scholar and internet search engines were used to search scientific literature, case studies and media records.

\section{Background}

Volcanic eruptions have direct impacts on communities at the time of the event and in the aftermath as well as at the eruption site and beyond the danger zone (Williamsen \& Courtney 2018). With regard to livestock emergency management, it is useful to distinguish between fast- and slow-onset disaster events with long or short durations that are large or small-scale in combination with the chance and effects of the event. For example, droughts are usually a slow-onset event and can be manageable, but when they become wide-spread and longlasting they have the potential to cause significant human and animal causalities. Alternatively, cyclones and volcanic eruptions can be drastic events with high uncertainty and possibly high levels of localised fatalities and destruction of infrastructure and disruption to delivery of services.

Brown and co-authors (2018) updated and expanded a global volcano fatality database to include human fatalities from 1500 to 2017 involving 194 volcanoes in 38 countries, with most recorded in southeast and east Asia (approximately 50 per cent). Besides fatalities, there are more people whose lives and livelihoods are affected, including people living beyond designated highrisk hazard zones. Communities can also experience an influx of displaced people and animals and the disruption of local economies (Woo 2008). Statistics on the numbers of people affected by the world's major volcanic eruptions from 1900 to 2016 show that 8 of the top 10 most disruptive eruptions have taken place since 1990. The growth in population and in tourism has led to greater numbers of people being affected and Indonesia, the Philippines and Japan have the largest populations living within $100 \mathrm{~km}$ of an active volcano (Cotrell 2015).

Animal losses due to volcanic eruptions have been recorded from archaeological findings and historic diaries but are only recently being addressed in terms of mitigation and evacuation (FAO Regional Office for Asia and the Pacific 2021). Although the value of animals, particularly livestock for livelihood recovery, is increasingly acknowledged in disaster mitigation, animal evacuation is not yet common practice in the context of smallholder farms in developing countries. The focus remains on reducing human fatalities by evacuation, thus abandonment of animals is common. The rescue of animals is often left to non-government organisations. These rescue attempts can be frustrating and stressful for both farmers and rescuers. Coordinated collective efforts can improve emergency response and livestock emergency preparedness. However, collective effort coordination entails people as well as managing people and when 'people manage people', culture inherently plays a role. Fundamental to disaster mitigation and preparedness is the desire to control for more positive and/or less negative outcomes. Therefore, 'unhelpful' culture may be acknowledged, analysed, understood and managed. This notion overlooks culture as context.

\section{Cultural contexts}

Culture as a phenomenon is difficult to define but can be generally understood as socially shared belief and meaning systems that influence values, perceptions, social norms and behavioural practices of individuals and groups of people. People are born into a culture as they are born into a language. Cultures, like languages, have evolved with humans and their environments. Members of communities must make a livelihood and protect themselves from hazardous environments. They develop ways to reduce vulnerabilities and improve knowledge and give meaning to their lives and circumstances. These survival strategies, beliefs and social norms are passed on and shape the cultures. Communities near active volcanoes experience eruption threats and have developed coping strategies. Volcanic eruptions can cause unusual and traumatic experiences that can result in psychological trauma and have lasting consequences for communities. Cashman and Cronin (2008) examined how communities process events by developing volcano mythologies. Eyewitness reports from 2 eruptions (Mt. St. Helens, USA in 1980 and Monserrat in 1997) were compared with a myth from the Mt. Tarawera eruption in New Zealand in 1886 to uncover a structure for narratives leading to myths (shown in Table 1).

This myth ontology explains other documented myths, for example, Mt. Merapi (Donovan 2010), Mt. Kelud and Sinabung (Adreastuti et al. 2019), Mt. Arenal (Van Manen 2014) and Montserrat (Haynes, Barclay \& Pidgeon 2008). Myth structure narration varies by region and even between villages as they experienced different eruption histories (Donovan 2010). Chester and Ducan (2007) found that 35 of 51 records had religious 
M RESEARCH

Table 1: Narrative structure from eyewitness accounts to shaping a myth.

\section{Post-eruption eye witness reports characteristics}

Immediate records:

inconsistency (due to extreme stress)

struggle to put the event into context (being beyond experience and comprehension)

descriptions as if an (animated) hidden power was behind the event.

Reflections:

psychological unbelief processed first by rumour and media and later by folk songs (US) and poetry (Montserrat), using metaphorical language to express the 'unnatural' of the hazard

Harry Truman, who had refused to evacuate and got killed, became a mythological hero in songs (first in the USA, later adopted in Monserrat).

\section{Story elements or stages in shaping a myth}

Effects and impacts on the lives and land (e.g. ruined, burned, ugly, hunger, dead animals).

Supernatural/other world metaphors (e.g. blast stood up by something or someone).

Analogies for unfamiliar phenomena (e.g. black snowflakes, inky waterfall, fire snakes, avalanche of black chalk, waves lapping up on a beach).

Responsibility of a higher power (e.g. gods, spirits, authorities who should have warned).

When a story gets older and is repeatedly told, the supernatural and higher power elements in the tale structure gradually overtake the effects and analogy elements in the story, thus shaping a myth.

(Haynes, Barclay \& Pidgeon 2008; Armijos et al. 2017). Volcanoes, livelihoods and risks are viewed differently by 'insiders' and 'outsiders', further referred to as farmers and experts. Experts focus on preventing loss of life, whereas farmers can lose their life and livelihood. Generally, experts are scientifically trained and modern science (and policy-making) deals with risk and uncertainties by studying the 'unknown', using the information to calculate or model risk to be pre-empted, reduced or mitigated (Woo 2008). Instead, people in traditional settings may have learnt to be familiar with and have a sense of safety through repetition of stories and rituals. They focus on what is uneventful or protective to reduce uncertainty and develop trust (Schechner 1994).

A decision on whether to evacuate due to volcanic eruption is a risk and uncertainty decision. Various scientific disciplines define and study risk decision-making, whereby the level, kind and accuracy of information is an important factor. The human brain deals with informed risk and uninformed uncertainty in a different way. Known risk from past information can be assessed or calculated, but the brain cannot handle a 'no information' situation. It will reconstruct earlier information and come up with best guesses, analogies, stereotypic patterns and historic information (Kahneman, Slovic \& Tversky 1982). Communities near volcanoes rely on re-constructions of earlier information, such as plant and animal behaviour patterns, mythological explanations and oral history in association with previous eruptions (Torrence 2019, Donovan 2010). If earlier experiences of evacuations, including false alarms or encounters with authorities were not good, people associate evacuations with bad outcomes and may take a chance that an eruption may not take place or have limited effects. Another reason for not evacuating is due to a psychological phenomenon of 'unjustified sense of subjective immunity', causing a false sense of safety (Douglas 1985). If previous eruptions were long ago or mild and life continued as usual, people may feel safe even if the actual event poses danger. Schlele (1996) notes: 
... the volcano is not just a threat. It makes the land enormously fertile. .... The residents have their own perception about the dangers of Mount Merapl. Their belief in the spirits and the rituals related to these spirits provide them with a subjective sense of security and strengthen their resistance to the government's resettlement policy. (p.104)

Table 2 summarises the different and at times opposing values and outlooks of local communities versus external experts and official emergency approaches.

\section{Meaning of livestock}

People go to great lengths to safeguard animals (Mei 2013). Animals play an important role in livelihoods, both economically and socio-culturally, which can be associated with replaceability (see Table 3). This relates to the level of trauma inflicted when animals are lost. Livestock can be centrally placed in cultures. For example, in Melanesian islands of the Pacific region, pigs represent stored wealth interwoven with social structures and beliefs and treating pigs poorly will be punished in the afterlife (Rappaport 1984).

Table 2: Comparison of values and outlooks in emergency approaches.

\section{Local farming communities}

Safeguarding livelihoods, including livestock.

\section{External experts and official emergency approach}

Save as many lives as possible.

Scientific, quantified risk assessment: rational and logical approach to dealing with uncertainty.

Religious, spiritual beliefs and history and experiences of previous eruptions as approach to dealing with uncertainty.

Reliance on official (top-down) communication.

Relying on combination of official communication, media and 'shadow' networks.

Reconstruction - build back better.

Safeguarding social capital and livelihood resilience in reconstruction.

Source: Based on case studies by Haynes, Barclay and Pidgeon (2008); Donovan (2010); Schechner (1994); Schlele (1996); Van Manen (2014); Armijos and co-authors (2017).

Table 3: Livestock roles and replaceability.

\begin{tabular}{|c|c|c|}
\hline Livestock role & Main production system & Livestock replaceability \\
\hline
\end{tabular}

Food item Subsistence livestock systems Replaceable, if replaced by food (aid).

Economic - financial

product, production mean,

reproduction mean, asset
All livestock systems

(except purely subsistence)
Replaceable by food aid and insurance (sale and slaughtering), compensate for loss of income, livestock replacement takes time.

Not replaceable, animals with unique genetic traits and other unique animals with a specific economic function.
Social - status and (re)establish relations

Community livestock systems

Abstracted - for social, cultural or religious functions
Traditional livestock systems
Not replaceable, if qualities or uniqueness of animals matters.

Replaceable short-term, if animals matter only in numbers (swift replacement).

Irreplaceable, if animal is given symbolic identity. Loss can involve traumatic experience. Affectionate - animal, herd / flock, or species $\begin{aligned} & \text { Almost all livestock systems, individually } \\ & \text { based }\end{aligned}$
Irreplaceable, can involve traumatic experience. 
Similarly, emergency planners, policy makers, government authorities, animal welfare agencies and people in general, place value on animals. Legally, animals are regarded as 'private goods', but the meaning of animals can surpass property value. Animals are sentient beings and can be viewed in their abstracted value (Villanueva 2018), motivating animal rescuers and farmers to put their lives, health and wellbeing at risk. Scientists increasingly study animal welfare and advocate for contingency plans that include animals (Glassey \& Wilson 2011, Waiblinger et al. 2006). Animal welfare is becoming part of humanitarian and political agendas and an integral part of disaster mitigation and emergency preparedness (LEGS 2014).

\section{Emergency response}

Analysis of case studies indicated entry points and opportunities to plan and implement emergency responses in a people-oriented, culturally sensitive manner.

\section{Connections and communications}

Van Manen (2014) and Haynes, Barclay and Pidgeon (2008) illustrate that cultural and socio-economic factors affect hazard knowledge and risk perceptions of local communities. Miscommunication and distrust are common and varying levels of distrust, local knowledge and rumours may compete with official information. Haynes, Barclay and Pidgeon (2008) indicate that scientists are a more trusted source of official information than government but scientists seldom play a role in emergency response communication. Such disconnects combined with a lack of feedback mechanisms and local consultation can lead to distrust and un- or under-preparedness of local communities. Typical emergency participants and information flows are presented in Figure 1, with official communication indicated by the broad arrows and the informal communication by the narrow arrows.

\section{Building trust and agency}

Armijos and co-authors (2017) describe a 'shadow' network alongside and interacting with formal disaster response institutions. This network evolved after the eruption of the Tunguraha Volcano in Ecuador in 1999. Official emergency response had been chaotic and there was a forced evacuation. Distrust in authorities and scientists became widespread. Afterwards, scientists reached out to villagers to develop a common vocabulary and establish shared knowledge that linked the informal community networks with formal government networks. The government decentralised risk management, conducted response trainings and improved shelter and infrastructure. During subsequent eruptions (2006 and 2014) villagers self-evacuated with their animals after direct communication from scientists and as assisted by authorities. Each village decided its risk tolerance and hour of evacuation and evacuated collectively. In addition, partial evacuations were facilitated for farmers with day jobs near their shelter home. The government took care of transport and assisted in a local 'feed for animals' distribution program. This approach of peoplecentred early warning and evacuation saved lives, including animals. Self-evacuation, however, would not have worked if there was no appropriate shelter for people and animals and if people's livelihoods were drastically affected.

\section{Village level emergency planning}

Donovan (2010) describes the influence of traditional cultural values during the 2006 volcanic crisis at Mt. Merapi in Indonesia

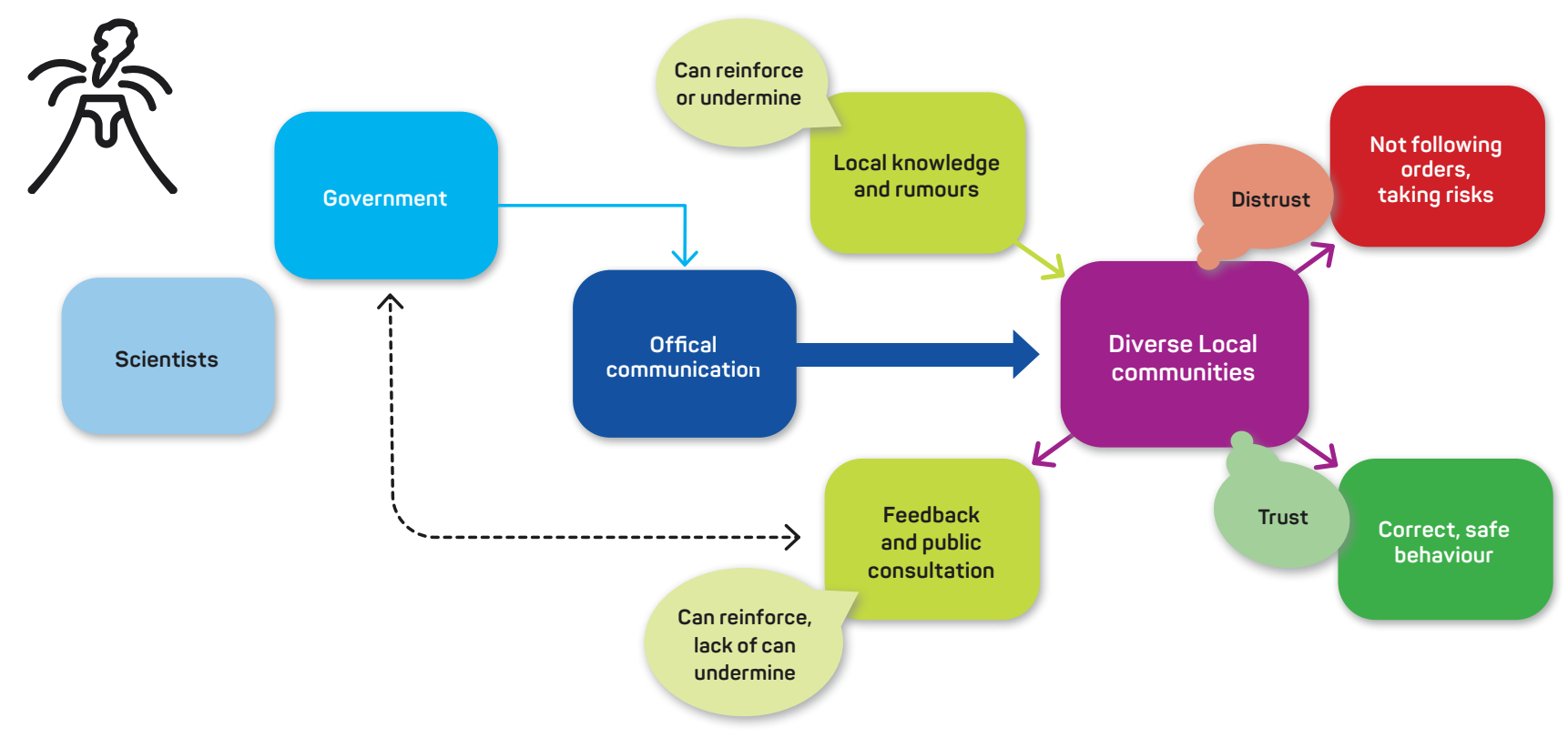

Figure 1: Typical participants and information flows in emergency communications. 


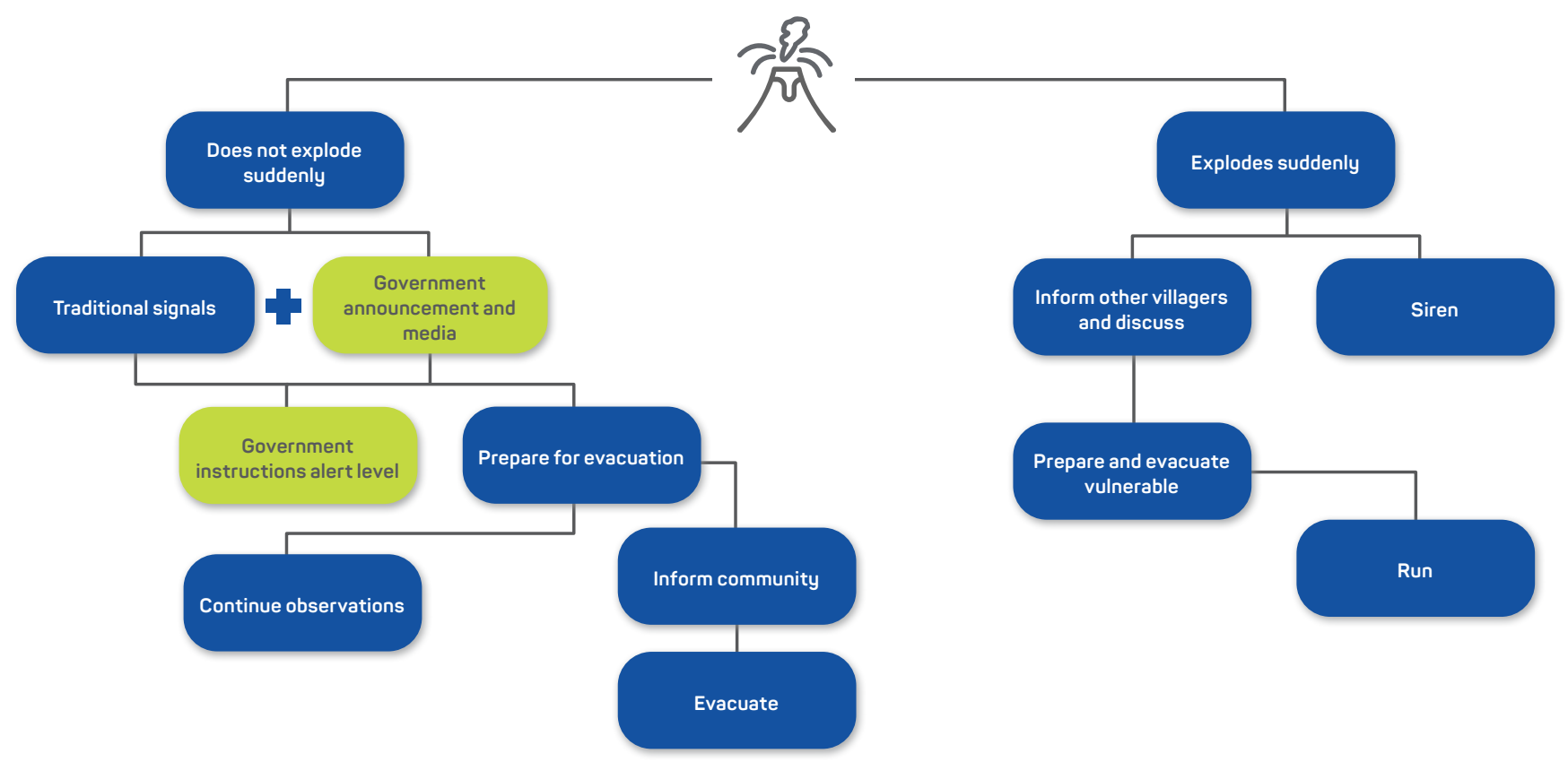

Figure 2: A summary of the Pelem Sari village emergency plan.

in 2 villages where people had refused to evacuate. Participatorybased village workshops included hazard mapping and village emergency plans. Figure 2 is a summarised version of the Pelem Sari village emergency plan, adapted from Donovan (2010, p.123). The decision tree shows an emergency plan in which traditional signals are important next to government warnings. It also shows the importance of informing others, community decision-making and planning, even during the emergency. In the group discussion, Donovan (2010) noted that, 'villagers would not take action unless they had received both a traditional and an official warning' (p.122). Figure 2 shows instances where outside 'government' information was received or considered by the Pelem Sari villagers (marked in yellow). Andreastuti and coauthors (2019) indicate that the most common problem arising during volcanic eruptions is a breakdown in communication between scientists, decision-makers and threatened communities. Mapping out the emergency planning processes in a participatory manner at the village level and mapping the connections to outside information sources improves both cultural insights and communication flows and supports emergency planning. It also offers opportunity to discuss the best approach for including livestock in emergency plans.

\section{Social capital and livelihood resilience (pre- and post-eruption)}

Social capital, the potential to benefit from social relations, is especially important during crises. When a community falls apart, for example when community members evacuate to different locations or die, there is a loss of supportive livelihood arrangements (Cox \& Perry 2011). Social relations can be comforting, inspiring and a collective narrative can help individuals adopt recovery strategies (Cashman \& Cronin 2008, Chamlee-Wright \& Storr 2011).
After the 2004 Indian Ocean tsunami, James and Paton (2016) found that women under 15 or over 60 years of age, femaleheaded households and people with disability were easily overlooked in aid and recovery programs. Moreover, they had difficulties accessing help, resources, financial credit and influencing policy. Gender, age, ability and social privilege become denominators for wealth distribution, dependency, ownership, resource access and political power (Speranza, Wiesmann \& Rist 2014). These 'denominators' mirror the capacity to (re)build livelihoods, unless counteracted upon. During recovery and reconstruction, social capital is critical for mobilising collective action to rebuild community property as well as reshape livelihood resilience and community strength. Nakagawa \& Shaw (2004) compared community recoveries after earthquakes in India and Japan and showed that high social capital in combination with community leadership provides a speedy and satisfying recovery.

Strong livelihoods can better withstand and recover from disaster. Haynes, Barclay and Pidgeon (2008) advocate to shift priority in emergency management strategies from hazard exposure reduction to tackling the root causes of livelihood vulnerability and boosting livelihood resilience.

\section{Livestock emergency preparedness}

Pre-eruption preparation should focus on people more than animals. This can take the form of knowledge exchange (from an intercultural perspective) on volcanic eruption risk assessment and (livestock) emergency management, building trust and intercultural communication plans. Turning to the integration of livestock concerns in emergency response, more governments start to get involved in animal emergency preparedness. The Philippine Daily Inquirer of 17 January 2020 included passages by Matthew Reysio-Cruz that illustrate how non-government 
" RESEARCH

Table 4: People-oriented, culture-sensitive emergency preparedness for people and animals.

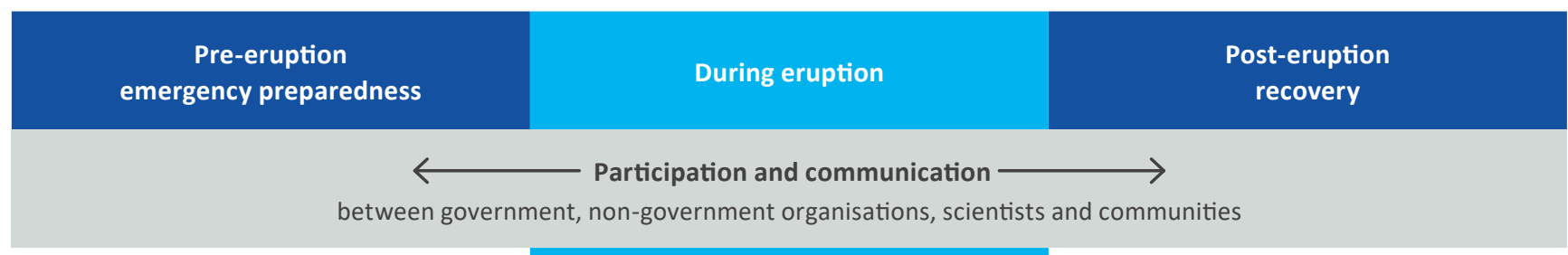

\begin{tabular}{|c|c|c|}
\hline $\begin{array}{l}\text { Acknowledge culture and experience, } \\
\text { develop common vocabulary and dialogue }\end{array}$ & Respect & Evaluation and feedback \\
\hline $\begin{array}{c}\text { Village Emergency planning, connect to } \\
\text { these. }\end{array}$ & Implement plans & Evaluation and feedback \\
\hline Building trust & Maintain trust & Build further trust \\
\hline 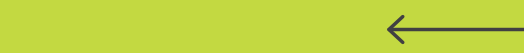 & Focus on livelihoods and social capital & $\longrightarrow$ \\
\hline $\begin{array}{c}\text { Increase livelihood resilience, agency, } \\
\text { leadership }\end{array}$ & Trade-off risks vs livelihood & $\begin{array}{l}\text { Restore or improve livelihood resilience, } \\
\text { attention for socio-psychological aspects. }\end{array}$ \\
\hline $\begin{array}{l}\text { Setting priorities, including livestock. } \\
\text { Assist with shelter, feed, transport, } \\
\text { communication preparations }\end{array}$ & Implement accordingly & Evaluation and feedback \\
\hline $\begin{array}{l}\text { Acknowledge diversity in community } \\
\text { (gender, age, social class) }\end{array}$ & $\begin{array}{l}\text { Ensure all groups included in emergency } \\
\text { support }\end{array}$ & $\begin{array}{l}\text { Focus recovery on all groups, especially most } \\
\text { vulnerable }\end{array}$ \\
\hline
\end{tabular}

organisations and government joined forces in the rescue of horses during the 2020 Taal eruption:

Animal rights organizations had complained that the military initially prohibited residents from taking animals with them....officials called an emergency meeting that day with animal welfare organizations ... [and others] to coordinate their efforts, putting an end to chaos that marked rescue efforts on previous days when the groups struck anywhere they were needed.... There's now a plan for the animals to also be part of the evacuation.

Volcanic eruption responses are complex and require leadership and clear communication at every level. Combined with livestock evacuations, complexity increases. In densely populated volcanic areas with small-scale farming, the logistics and shelter provision can be challenging. However, the people-oriented emergency preparedness approach that Ecuador took, suggests that animal evacuation is feasible; demographics and politics allowing. Evacuations or de-and-restocking of animals in great numbers and on short notice needs good preparation and coordination involving farmers. Participatory tools (e.g. Participatory Response Identification Matrix) for scoring livelihood objectives, emergency phases and technical interventions, such as destocking and restocking and veterinary support (LEGS 2014), can be suitable for slow disaster management. Pre-eruption uncertainties hamper trade-off decision-making between risk and livelihood. However, a post-eruption situation involving livestock can develop into a slow disaster crisis.

Ensuring livelihood continuity is essential. Therefore, facilitating evacuation, insurance options, innovative adaptations to protect and care for livestock and improve livelihood resilience and animal health are priorities. Experts should be cautious to 'do the thinking' for farmers and come up with ill-adapted solutions, for example, cyclone shelter homes not catering for livestock. (Miyaji et al. 2020). Exchanges between communities of experiences and local adaptations are deemed more appropriate and thus more successful.

\section{Framework for addressing cultural factors}

These case studies on emergency preparedness in volcanic areas uncovered a number of commonalities, even though cases are located in communities across several continents. The patterns identified allow a comparison of emergency preparedness by local farming communities versus externally 
imposed emergency preparedness approaches. They point to connecting and communicating in a participatory manner as well as acknowledging that livelihood continuity and social capital play important roles for people-oriented, culture-sensitive (livestock) emergency preparedness. Table 4 summarises the framework.

Lessons learnt during post-eruption evaluation generate new knowledge for preparing for a next eruption threat. The psychological-cultural factors that influence communities' evacuation willingness and preparedness cannot be 'solved' but they can change with new experience and knowledge. A peopleoriented approach that seeks to understand the underlying values and outlooks, combined with feedback and interaction processes would be constructive for bridging differences and building trust. Developing a common vocabulary to avoid misinterpretations is part of this process (Armijos et al. 2017).

Since livestock evacuation decisions are a trade-off between risk and livelihood. farmers assess a tolerable or acceptable risk. Safeguarding livestock during an emergency situation and increasing livelihood resilience may be prioritised (Haynes, Barclay \& Pidgeon 2008). Albeit, a people-oriented culturesensitive approach with consultation needs to come first. Then, if it transpires that people's priorities concern their livestock; this should be incorporated in the emergency preparedness approach.

Culture and livelihood embedded risk perceptions and attitudes of scientists and policy makers versus those of residents also needs to be understood and taken into consideration to identify effective communication strategies (Doyle et al. 2014). Local leaders and cultural interpreters play a pivotal role in understanding risk interpretation and messaging and should be consulted (Mangundjaya 2013).

\section{Conclusions and recommendations}

Taking an interdisciplinary phenomenological approach, this study shows that cultural factors, including the meaning of livestock and livelihood, play a role in evacuation reluctance. Example studies tested the pattern and observations from the literature reflection to develop a framework for culturally sensitive livestock emergency preparedness (and reconstruction) programs. The framework can clarify trade-off decisions between livelihood and risk (small-chance vs high-impact risk). How this translates to other types of disasters could be studied. It may be expected that different types of livestock contingency plans are needed, but that all disaster management could benefit from a people-oriented and culture-sensitive approach. Additionally, the contexts of countries differ in various ways and distances in cultural difference between residents, emergency managers and authorities can be significant.

In a people-oriented and culture-sensitive approach, one should be aware that emergency planners view situations as problems and they have been trained to analyse and solve them. By working in multidisciplinary teams, the scope broadens. However, looking through a culturally sensitive lens allows seeing the context. Culture sets the context of communities and also of emergency planners, government bodies and nongovernment organisations. In addition, women and men have different viewpoints. In a people-oriented approach this should be considered as women, men, young, old, disabled and poor are not equally vulnerable in crises situations. Therefore, it is vital to have female and male scientists, policy makers, communication experts, authorities and activists working together and with communities to better manage disaster events.

\section{References}

Andreastuti S, Paripurno ET, Gunawa H, Budianto A, Syahbana D, Pallister J 2019, Character of community response to volcanic crises at Sinabung and Kelud volcanoes, Journal of Volcanology and Geothermal Research vol. 382, pp.298-310. doi:10.1016/j. jvolgeores.2017.01.022

Armijos MT, Phillips J, Wilkinson E, Barclay J, Hicks A, Palacios P, Mothes P \& Stone J 2017, Adapting to changes in volcanic behaviour: Formal and informal interactions for enhanced risk management at Tungurahua Volcano, Ecuador, Global Environmental Change, vol. 45, pp.217-226. doi:10.1016/j. gloenvcha.2017.06.002

Brown P, Daigneault AJ, Tjernström E \& Zou W 2018, Natural disasters, social protection, and risk perceptions, World Development, vol. 104, pp.310-325. doi:10.1016/j.worlddev.2017.12.002

Cashman KV \& Cronin SJ 2008, Welcoming a Monster to the World: Myths, oral tradition, and modern societal response to volcanic disasters, Journal of Volcanology and Geothermal Research, vol. 176, no. 3, pp.407-418. doi:10.1016/j. jvolgeores.2008.01.040

Chamlee-Wright E \& Storr VH 2011, Social Capital as Collective Narratives and Post-Disaster Community Recovery, The Sociological Review, vol. 59, no. 2, pp.266-282. doi:10.1111/j.1467954X.2011.02008.x

Chester D \& Duncan A 2007, Geomythology, theodicy and the continuing relevance of religious worldviews on responses to volcanic eruptions, In: Grattan J \& Torrence R (eds) Living Under the Shadow: The Cultural Impacts of Volcanic Eruptions, Left Coast Press, Walnut Creek CA, USA. doi:10.4324/9781315425177

Cottrell E 2015, Chapter1-Global Distribution of Active Volcanoes. Volcanic Hazards, Risks and Disasters, Elsevier, pp.1-16. doi:10.1016/B978-0-12-396453-3.00001-0

Cox R S \& Perry KME 2011, Like a Fish Out of Water: Reconsidering Disaster Recovery and the Role of Place and Social Capital in Community Disaster Resilience, Am J Community Psychology, vol. 48, pp.395-411. doi:10.1007/s10464-011-9427-0

Donovan K 2010, Doing Social Volcanology: Exploring volcanic culture in Indonesia, Area, vol. 42, no. 1, pp.117-126. doi:10.1111/ j.1475-4762.2009.00899.x

Douglas M 1985, Risk Acceptability According to Social Sciences, Russell Sage Foundation, New York.

Doyle EEH, McClure J, Paton D \& Johnston DM 2014, Uncertainty and decision making: Volcanic crisis scenarios, International Journal of Disaster Risk Reduction, vol. 10, pp.75-101. doi:10.1016/j.ijdrr.2014.07.006 
FAO Regional Office for Asia and the Pacific 2021, New agreement to protect vulnerable family farmers and their farm animals from volcanic eruptions takes shape in the Asia-Pacific region. At: www. fao.org/asiapacific/news/detail-events/en/c/1294336/.

Glassey S \& Wilson TM 2011, Animal welfare impact following the 4 September 2010 Canterbury (Darfield) earthquake, Australasian Journal of Disaster and Trauma Studies, 2011-12 (Special Issue: A Focus on the Canterbury), pp.49-59.

Haynes K, Barclay J \& Pidgeon N 2008, Whose reality counts? Factors affecting the perception of volcanic risk, Journal of Volcanology and Geothermal Research, vol. 172, pp.259-272. doi:10.1016/j.jvolgeores.2007.12.012

Herrero M \& Grace D \& Njuki J \& Johnson N \& Enahoro D \& Silvestri S \& Rufino M C 2013, The roles of livestock in developing countries, Animal, vol. 7, no.S1, pp.3-18. doi:10.1017/S1751731112001954

James H \& Paton D 2015, Social Capital and the Cultural Contexts of Disaster Recovery Outcomes in Myanmar and Taiwan, Global Change, Peace and Security, vol. 27, no. 2, pp.207-228. doi:10.108 0/14781158.2015.1030380

Kahneman D, Slovic P \& Tversky A 1982, Judgment Under Uncertainty: Heuristics and Biases, Cambridge University Press, New York USA.

Latour B \& Woolgar S 1986, Laboratory Life: The construction of scientific facts, Princeton University Press, New Jersey USA.

Livestock Emergency Guidelines and Standards Project (LEGS) 2014, Livestock Emergency Guidelines and Standards, 2nd edition Rugby, UK, Practical Action Publishing. doi:10.3362/9781780448602

Mangundjaya WLH 2013, Is there cultural change in the national cultures of Indonesia? In Kashima Y \& Kashima E S \& Beatson $R$ (Eds.), Steering the cultural dynamics: Selected papers from the 2010 Congress of the International Association for Cross-Cultural Psychology. At: https://scholarworks.gvsu.edu/iaccp_papers/105/.

Miyaji M, Okazaki K \& Ochiai C 2020, A study on the use of cyclone shelters in Bangladesh, Japan Architectural Review, vol. 3, no. 4, pp.590-600.

Mei ETW, Lavigne F, Picquout A, de Bélizal E, Brunstein D, Grancher D, Sartohadi J, Cholik N \& Vidal C 2013, Lessons learned from the 2010 evacuations at Merapi volcano, Journal of Volcanology and Geothermal Research, vol. 261, pp.348-365. doi:10.1016/j.jvolgeores.2013.03.010

Nakagawa Y \& Shaw R 2004, Social Capital and Disaster Recovery: A Comparative Case Study of Kobe and Gujarat Earthquake, 13th World Conference on Earthquake Engineering Vancouver, B.C., Canada, August 1-6, 2004. Paper No. 771.

Rappaport RA 1984, Pigs for the Ancestors: Ritual in the Ecology of a New Guinea People, second edition, Yale University Press, New Haven, USA.

Schechner R 1994, Ritual and Performance, In Ingold, T. Companion Encyclopedia of Antropology, Routledge, London, New York, pp.613-645.

Schlehe J 1996 Reinterpretations of Mystical Traditions. Explanations of a Volcanic Eruption in Java, Anthropos, vol. 91, pp.391-409. At: www.jstor.org/stable/40464497.
Speranza Cl, Wiesmann U \& Rist R 2014, An indicator framework for assessing livelihood resilience in the context of socialecological dynamics, Global Environmental Change, vol. 28, pp.109-119. doi:10.1016/j.gloenvcha.2014.06.005

Torrence R 2019, Social responses to volcanic eruptions: A review of key concepts, Quaternary International, vol. 499, Part B, pp.258-265. doi:10.1016/j.quaint.2018.02.033

Van Manen S 2014, Hazard and risk perception at Turrialba volcano (Costa Rica); implications for disaster risk management, Applied Geography, vol. 50, no. 6, pp.3-73. doi:10.1016/j.apgeog.2014.02.004 Villanueva G 2018, Against Animal Liberation? Peter Singer and His Critics, SOPHIA, vol. 57, pp.5-19. doi:10.1007/s11841-017-0597-6

Waiblinger S, Boivin X, Pedersen V, Tosi MV, Janczak AM, Visser EK \& Jones RB 2006, Assessing the Human-Animal Relationship in Farmed Species: A critical review, Applied Animal Behaviour Science, vol. 101, nos. 3-4, pp.185-242. doi:10.1016/j.applanim.2006.02.001

Williamson F \& Courtney C 2018, Disasters fast and slow: The temporality of hazards in environmental history, International review of environmental history, vol. 4, no. 2, pp.5-11.

Woo G 2008, Probabilistic criteria for volcano evacuation decisions, Nat Hazards, vol. 45, pp.87-97. doi:10.1007/s11069-007-9171-9

\section{About the authors}

Dr Marjan Leneman is trained in veterinary epidemiology and culture anthropology at Utrecht University (The Netherlands), University of Zimbabwe and University of Reading (United Kingdom) and has worked in private veterinary practice, for the United Nations Food and Agriculture Organization and the International Livestock Research Institute. She has worked on risk strategies and organisational development in areas of emergency preparedness, behavioural research, social inclusive development and capacity building.

Ir Eva Jordans is trained in land and water management at Wageningen University and Research in (The Netherlands) and intercultural communication at University of Bedfordshire (United Kingdom). She has 30 years' experience in project management, intercultural leadership development and executive directorship in Asia, Africa and Europe. She works as an independent management consultant supporting development programs in Africa and Asia.

Dr Katinka de Balogh is a veterinarian with over 30 years' experience in international development, animal and zoonotic disease control, outbreak investigation and crisis management. She has worked in the World Health Organization and as a lecturer at the veterinary faculties in Zambia, Mozambique and the Netherlands. She is working for the Food and Agriculture Organization in Rome and is Senior Animal Health and Production Officer at the FAO based in Bangkok where she is the lead technical officer for projects ranging from animal production and breeding to controlling epizootics and disaster response. 